\title{
Psychosocial skill development among community levels workers working with children in difficult circumstances
}

\author{
U Harikrishnan', P Kavitha², S Rajamanikandan ${ }^{3}$, K Sekar $^{4 *}$, E P Marykutty ${ }^{5}$ \\ ${ }^{1,3,5} \mathrm{Ph}$ D Scholar, ${ }^{2}$ Project Coordinator, ${ }^{4}$ Professor, ${ }^{1,5}$ Dept. of Social Work, ${ }^{3,4}$ Dept. of Psychiatric Social Work, ${ }^{1}$ School of Social Sciences, \\ Mizoram University, Mizoram, ${ }^{2}$ Kaval Project - Govt. of Kerala in Collaboration with NIMHANS, Bengaluru, Karnataka, ${ }^{3,4}$ NIMHANS, \\ Bengaluru, Karnataka, ${ }^{5}$ Christ University, Bengaluru, India \\ *Corresponding Author: K Sekar \\ Email: sekarkasi@gmail.com
}

\begin{abstract}
Community Level Workers (CLWs) are the first respondents to Children in Difficult Circumstances/Need of Care and Protection $(\mathrm{CDCs} / \mathrm{CNCP})$. The study aims to develop community resource building on preventive and promotive psychosocial interventions for children in difficult circumstances. The study adopted a quasi-experimental research design with pre \& post assessment carried out among the trained CLWs after 16 hours of capacity building program conducted through two days residential training. The training programme was conducted in nine different places across Kerala where Jyothis Charitable Society, Kottayam, Kerala (Reg no: k368/2008) is extending its services. The training focused on Life Skills Education (LSE) \& Student Enrichment Program (SEP) for CDCs/CNCP, facilitated by Master Trainers (MTs) with the hand holding support from NIMHANS. A total of 207 female with a mean age of $40.42 \pm 12.64$ years and had $10.30 \pm 8.97$ years of experience working as CLWs. Majority of the participants were teachers (64\%). The mean knowledge score of the participants increased from 2.04 to $7.78(\mathrm{P}<000)$ after the training. Capacity building of the grass root level workers will aid in early identification of psychosocial problems among children in difficult circumstances. This will further support in developing skills to address the varied psychosocial issues faced by children in their daily life and education. Life skills educational program and student enrichment program would help children in dealing with challenges in daily life and cope with them effectively.
\end{abstract}

Keywords: Capacity building, Psychosocial interventions, Children in difficult circumstances, Community level workers.

\section{Introduction}

The curative, preventive and promotive aspects of mental health for Children in Difficult Circumstances and Children in Need of Care and Protection need to reach to the grass root level to ensure holistic care and protection of the most marginalized children. Added to stigma is the lack of mental health professionals that creates a gap in the provision of services which causes a major hindrance to reach out to the most marginalized children. ${ }^{1}$ Children are vulnerable and look upon to the elders in challenging situations for support. Children in difficult circumstances experience multiple risks that affect their physical and mental health. Issues related to children are increasing in terms of sexual abuse, physical violence, poor parental care, poor support from family, school and community. ${ }^{2}$ Children living in such insecure environment experience varied psychosocial problems that are beyond the level of coping which will be manifested as emotional and behavioral disturbances.

The chances of a child encountering difficulties leading to insecure, faulty and non-conducive environment are very high. These children experience lack of care and protection, as well as poor support system. ${ }^{3}$ The preventive and promotive interventions among children in difficult circumstances through life skills education and student enrichment program enhances their mental health. A Meta analytical study on impact of enrichment programs among students from 1985 to 2014 where 26 studies across the world was analyzed showed positive impact on academic achievement and socio emotional development. ${ }^{4}$ Enrichment programs promote individual and social development and minimize social problems faced by children. This highlights the need of enrichment programs and to ensure positive mental health among CDCs/CNCPs. Stephan (2009) highlighted the importance of gender roles that specifies the effective ways of dealing with child specifically the effective ways adopted by females that is being nurturing, sensitive and emotional..$^{5}$ A Study by Haji (2011) reported that life skills education is highly effective in enhancing happiness, quality of life, and emotional regulation among children. ${ }^{6}$ The Mental health gap a challenge due to paucity in number of mental health professionals is a major block in reaching out to CDC's /CNCP's. Developing resource at grass root level by training community level volunteers at varied levels of care would address the issue and ensure the provision of services to the unreached child population in the rural community. CLWs that can be trained in the area include Teachers, Health workers, ASHA workers, Social workers, NGO or volunteers working among the CDCs /CNCP. The current study is to determine the impact of training on knowledge among community level workers working with children in difficult circumstances on life skills education and student enrichment program for children.

\section{Methodology}

The current study adopted quasi experimental research design with pre and post assessment among the 207 community level workers working with Jyothis Charitable Society, Kerala. The first phase of the program consisted of a five days TOT workshop on Psychosocial Care for Children in Difficult Circumstances to train the Master Trainers (MTs) from Jyothis Chartable Society at Department of Psychiatric Social Work, NIMHANS.7 The current study is second phase of the program. The trained 
MTs organized a 16 hours training spread across two days for the community level workers of Jyothis Charitable Society with the handholding support from NIMHANS. The major components of the two days training were NIMHANS model of LSE\& SEP for Children in Difficult Circumstances. ${ }^{8,9}$ The training program aimed at developing knowledge and skills among the community level workers to work with children in difficult circumstances. The evaluation of the same was conducted before and after the training to assess the impact of training in their in knowledge.

Participatory methodology such as activities, group discussion, brainstorming and role-plays were adopted in the training. The first day training focused on Life Skills Education i.e. Decision Making and Problem Solving; Creative and Critical Thinking; Effective Communication and Interpersonal Relationship; Empathy and SelfAwareness; Coping with Stress and Coping with Emotions and feedback. The second day focused on Student Enrichment Program that covered topics such as Study Habits; Exam Preparation; Healthy Life; Physical Health and Mental Health; and Time Management.

The MTs (CLVs) conducted the training programme in nine different field area of Jyothis Charitable Society across Kerala. Two training faculties from NIMHANS provided handholding support for the Master Trainers. The current study was a part of NIMHANS project and approved by institute project section with reference of GOKE/002/207/2017/00998.

\section{Results}

Assessment was carried out on the socio demographic profile and difference in the knowledge before and after the training among the community level workers to understand the effectiveness of the program.

\section{Socio demographic profile}

Table 1: Socio demographic details of CLWs - N=207

\begin{tabular}{|l|c|c|c|}
\hline \multicolumn{2}{|c|}{ Domain } & N & \% \\
\hline \multirow{4}{*}{ Religion } & Hindu & 25 & 12.1 \\
\cline { 2 - 4 } & Christian & 182 & 87.9 \\
\hline \multirow{4}{*}{ Education } & SSLC & 09 & 04.3 \\
\cline { 2 - 4 } & Higher & 45 & 22.7 \\
& Secondary & & \\
\cline { 2 - 4 } & Under Graduate & 96 & 46.4 \\
\cline { 2 - 4 } & Post Graduate & 57 & 27.5 \\
\hline \multirow{3}{*}{ Occupation } & Teacher & 133 & 64.3 \\
\cline { 2 - 4 } & Social Worker & 18 & 08.7 \\
\hline
\end{tabular}

\begin{tabular}{|l|c|c|c|}
\hline & Coordinator & 56 & 27.1 \\
\hline $\begin{array}{l}\text { Attended any } \\
\text { training program }\end{array}$ & No & 177 & 85.5 \\
\cline { 2 - 4 } & Yes & 30 & 14.5 \\
\hline
\end{tabular}

Socio demographic profile of the participants assessed showed that all the participants who attended were female, and the mean age was $40.42 \pm 12.64$ (Mean $\pm \mathrm{SD}$ ) years. The mean years of experience working with children was $10.30 \pm 8.97$ and majority of the participants were from rural background. The distribution of religion among the participants (CLW's) showed that (88\%) belonging to Christianity. A little lesser than half of the participants (46.4\%) were under graduates (UG) and post graduates formed $27.5 \%$. The results confirm good educational background among the community level volunteers where $3 / 4^{\text {th }}$ of the population had educational back ground of more than 15 years. The occupational status of the participants showed that majority of them were teachers who had direct contact with children $(64 \%)$, others were social workers and coordinator who had secondary contacts with children. Higher proportion of the participants $(86 \%)$ had not attended training on the topic before.

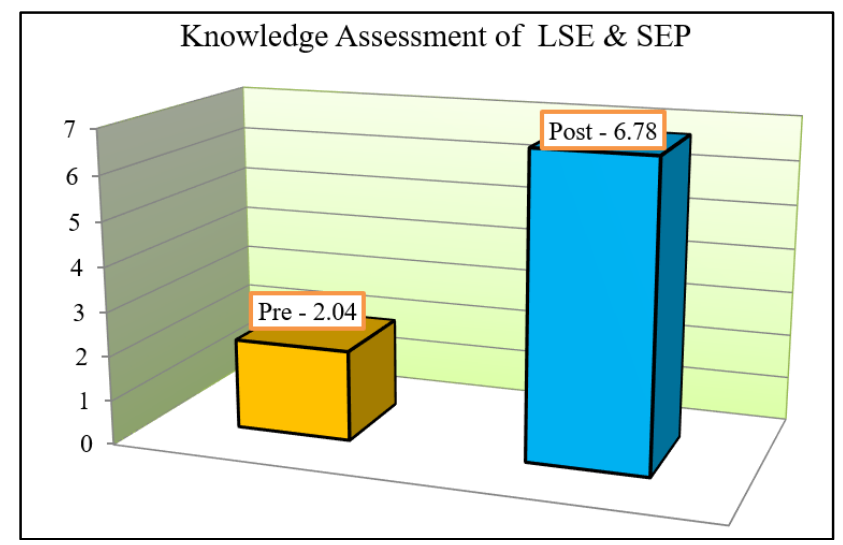

Fig. 1: Pre and Post-test assessment on LSE \& SEP for CDCs among CLWs.

Fig. 1 gives the result of Pre and Posttest assessment among CLW's on Life Skills Education (LSE) and Student Enrichment Program (SEP). The results of the pre and post assessment conducted show that the knowledge has increased significantly among the participants. The mean knowledge among the participants after the training increased to $6.67 \pm 1.02$ from $2.04 \pm 1.46$. Paired sample t-test conducted identified that the increase in the knowledge after the training was highly significant $(t=-45.93, \mathrm{df}=206$, $\mathrm{P}=.000)$.

Table 2: Overall evaluation of workshop among CLWs

\begin{tabular}{|l|c|c|c|c|}
\hline Variables & Very good & Good & Average & Poor \\
\hline Structure \& Organization & $114(55.1)$ & $93(44.9)$ & $00(0)$ & $00(0)$ \\
\hline Usefulness & $141(68.1)$ & $66(31.9)$ & $00(0)$ & $00(0)$ \\
\hline Practical Orientation & $106(51.2)$ & $101(48.8)$ & $00(0)$ & $00(0)$ \\
\hline Overall program & $90(43.5)$ & $117(56.5)$ & $00(0)$ & $00(0)$ \\
\hline
\end{tabular}


A feedback was taken from the CLWs in four areas such as structure and organization, usefulness, practical orientation and overall impression about the program. The first area on "structure and organization" of the content of the program that included theoretical information of each session and methodology adopted for transfer of knowledge ranged from very good $(55.1 \%)$ to good $(44.9 \%)$. The "usefulness" of the program was assessed among the participants to understand the relevance of life skills education and student enrichment program in their regular work in addressing the issues of children. Positive result confirming the usefulness of the module was obtained that ranged between very good $(68.1 \%)$ to good $(31.9 \%)$. The training was activity based with specific activities on each topic followed by discussion after the activity to relate the topic with the real life situation towards making the concept clear and adaptable to real life situation. The results on the "practical orientation" focused on the skill achievement among the trainees to carry out the program with children showed a positive result where the respondents opined that the practicality of the program ranged between very good $(43.5 \%)$ to good $(56.5 \%)$.

The overall evaluation about the program among participants showed that the program was effective enough to answer the challenges faced by children as observed by the community level workers through life skills education as well as, study related issues among children through student enrichment program.

\section{Discussion}

Community level workers in NGOs and in Government sectors such a ASHA workers and ICDS workers play a major role in reaching out to children in communities. They need to be equipped with knowledge and skills to identify psychosocial issues and provide psychosocial first aid and interventions. This is very much essential to address the gap of mental health professionals to reach out to unreached populations. De professionalizing social work approaches to reach out to the unreached and underprivileged children and ensuring psychosocial interventions at curative, preventive and promotive levels are well documented by Kavitha and Sekar (2015). The current population of community level workers was working with underprivileged and highly vulnerable children in rural areas from backward communities were scarcity in provision of mental health services by professionals is reported. The trained community level workers will be able to provide psychosocial care and support for children as proved by the studies carried out in similar line previously. These community level workers were working as teachers in the schools and the community resource centers run by Jyothis Charitable Society who work with children on a regular basis as teachers as well as child supporters. The majority of the teachers being women may work out positively for the implementation of the program as reported by Stephan (2005) that emphasizes the significant role played by female teachers in dealing with children by being nurturing, sensitive and emotional. ${ }^{5}$

Professional competency is essential to address the psychosocial issues among children. The mental health gap in the area reported that there is a concern to reach out to the unreached children especially in rural communities. Kavitha and Sekar (2015) reported the method of deprofessionalizing social work approach by building up capacity of the community level workers directly working with children to reach out to children in difficult circumstances and ensure the availability of psychosocial services that are curative, preventive and promotive in nature. ${ }^{1}$ The current population trained was mostly from rural background working with children in rural area where the availability of mental health services is less. Moreover the majority of participants were teachers who have direct contact with children. Hence the occupation and the gender of the participants will work as positive factors to reach out the children in difficult circumstances. ${ }^{5}$

Teachers are the primary contact persons for children in school. Teachers will be able to identify the psychosocial problems in children as early as possible. For eg: a sudden drop in academics, which is an indicator of multiple problems faced by the child, can be identified by a trained teacher. The teacher can support the child to manage the problem at first level as well as addressing the issue of poor educational performance which is an offshoot of the multiple problems faced by the child. The NGO coordinators as well as psychiatric social workers can guide the teachers and community level workers by extending monitoring and support services in effectively carrying out the program.

The structure, organization, usefulness and practical orientating determine the effective ness of skill building program to enhance the confidence and ease to carry out the program with children. The activity-based approach is selfexplanatory and proved to be the best methodology for training community level workers by many studies ${ }^{8-11}$ was adopted in the current skill building program. The effectiveness of life skills programs to enhance positive mental health to uphold happiness, ${ }^{12,13}$ emphasized on improving quality of life and emotional regulation, ${ }^{6}$ deal effectively with demands and challenges of everyday life, positive actions to protect themselves and promote healthy and meaningful social relationship. ${ }^{14}$ The effectiveness of enrichment programme is well explained through Meta analytical study ${ }^{4}$ for three decades that identified a positive impact on students' academic achievement and socioemotional development. The current module which is an amalgamation of life skills education and student enrichment program has dual effect on children i.e. promoting mental health and enhancing education performance among children which is essential as far as school going children are concerned to develop skills to address day to day stressors in life, ensuring positive mental health and performing well in academics by adopting good study habits preparing well for examinations there by ensuring academic achievements. The training not only enhances the academic performance the topics on maintaining good physical and mental health and daily scheduling will give children the perspective of holistic 
living which is essential to maintain a well-balanced life. The feedback on the overall program confirms the understanding of the participants on the aspect that training reached to felt need of the participants while working with children. The contents were effective to address the felt needs of participants and the participatory methodology supported the effectiveness of the program in reaching out to CDCs. The results of the current study confirms the finding of the studies in similar lines carried out earlier by the researchers there by confirming the relevance of community resource building among community level workers to reach out to provide psychosocial care for children in difficult circumstance $s$

The most appropriate method of imparting knowledge on Life Skills \& Student Enrichment program for children is through CLWs. Therefore, there essential to develop professional knowledge and skills among the CLWs to provide psychosocial care for CDCs. ${ }^{1}$ The program will reach out to the children in need of support as the program is incorporated with the regular child care activities of Jyothis Charitable society thereby ensuring effective implementation of the program showing positive results comparable to that of previous works in the similar area, ${ }^{1,3,11,13}$ there by confirming the effectiveness of two days module in enhancing knowledge and skill among the community level workers and supporting children in difficult circumstances through provision of psychosocial care.

\section{Conclusion}

Children especially in difficult circumstances face multiple problems in life which is psychosocial in nature. These multiple problems faced by the children are beyond their coping that will be manifested as behavioural and emotional problems. Children in difficult circumstances need care and support from responsible adults. Many a times they lack the support and care from the adults. This issue can be addressed by supporting children using available community resources i.e community level workers, working in Non-Governmental Organizations, ASHA workers, ICPS workers etc. The significance of training programs in social work is to assist the practice of psychiatric social work approach to people who need services. The social work practices should reach to the most needed population who are unreached due to socio economic, geographic and cultural factors. The trainings focusing on developing skills among the community level workers who directly support children and provide necessary services is the most effective way of reaching out to the unreached children and ensuring their holistic wellbeing there by breaking the cycle of psychosocial problems that hinders the growth and development of children in difficult circumstances.

\section{References}

1. Kavitha P, Sekar K. Reaching the Unreached: DeProfessionalization of Social Work Education. Natl J Prof Soc Work. 2015;16:53-63.

2. UNICEF. The Situation of Children in India -A Profile. 2011. Retrived from www.unicef.in.

3. Kavitha P, Sekar K, Raj EA. Psychosocial Care for Children in Difficult Circumstances-A Community Based Approach. Natl J Prof Soc Work. 2012;13:28-41.

4. Kim M. A Meta-Analysis of the Effects of Enrichment Programs on Gifted Students. Gifted Child Q. 2016;60:102-16.

5. Stephens MA. Gender Differences in Parenting Styles and Effects on the Parent- Child Relationship. Texas State University-San Marcos. 2009. Retrieved from https://digital.library.txstate.edu/bitstream/handle/10877/3300/ fulltext.pdf

6. Haji TM, Mohammadkhani S, Hahtami M. The Effectiveness of Life Skills Training on Happiness, Quality of Life and Emotion Regulation. Procedia - Soc Behav Sci. 2011;30:40711.

7. Harikrishnan U, Kavitha P, Sekar, K, Marykutty EP. Assessment of knowledge on psychosocial care children in difficult circumstances; TOT workshop for community level volunteers. Res J Recent Sci. 2018;7:30-4.

8. Sekar K, Manoj K, Raj EA. Life Skills Education for Children in Difficult Circumstances - My WorkBook. Bangalore: NIMHANS; 2008.

9. Sekar K. Student Enrichment Programme - Workbook. Bangalore: NIMHANS; 2010.

10. Sekar K, Roncalli T, Aravindraj, Sanjeev K, Babu S Psychosocial care for chidlren in difficult circumstances Workbook: NIMHANS, Bangalore; 2012.

11. Sekar K, Kavitha P. Psychosocial Problems among Children in Difficult Circumstances. Artha J Soc Sci. 2015;14:53-70.

12. Amrei MT, Farahani A. The effectiveness of training life skills on happiness of students. WSN 2016;46:276-86. Retrieved from www.worldscientificnews.com

13. Pillai RR, Uthaman SP, Remya RNK. Impact of Psychosocial Care Training among Volunteers Working with Children in Difficult Circumstances. Natl J Prof Soc Work. 2015;16:23-33.

14. WHO. Life Skills Education for Children and Adolescents in Schools. 1997. Retrived from http://apps.who.int/iris/handle/10665/63552.

How to cite this article: Harikrishnan U, Kavitha P,
Rajamanikandan S, Sekar K, Marykutty EP. Psychosocial
skill development among community levels workers
working with children in difficult circumstances. Telangana
J Psychiatry. 2020;6(1):87-90.

How to cite this article: Harikrishnan U, Kavitha $\mathrm{P}$, Rajamanikandan S, Sekar K, Marykutty EP. Psychosocial working with children in difficult circumstances. Telangana

\section{Source of Funding}

None.

\section{Conflict of Interest}

None. 